latitudes during the Greenhouse Effect of the Third Millennium is provided by: (1) climatic and environmental data relating to the Warm Medieval Period in the Mediterranean area; (2) results achieved from research into geoenvironmental changes linked to historical climatic variations, especially those of the last few centuries, and; (3) various multidisciplinary data obtained from research conducted in various parts of the world (Fig. 2).

Instrumental data chiefly concerning the last 150 years in the Mediterranean show a consistently close correlation between environmental variations (increase in solar activity and temperature and changes in the quality and quantity of rainfall) and the period of transition from the cold-humid climatic conditions of the Little Ice Age to those that may probably characterise the Warm Period of the Third Millennium (Greenhouse Effect of the Third Millennium).

If cyclical climatic variation as occurred in the past will continue, it might result in new environmental conditions along the belts bordering the current climatic zones. In particular, a large part of the areas that are currently subtropical deserts might be transformed into humid areas. These conditions may be at times better and at times worse than those of the Little Ice Age.

This speculated shift in Mediterranean climatic conditions a few degrees to the north would cause an appreciable change in rainfall in central-northern Europe. Since the $18^{\text {th }}$ century, this area has been characterised by an almost homogeneous distribution of rainfall over the year and consequently, a constant river water regime. Mediterranean-type rainfall could probably increasingly affect this area in the near future. This seasonalisation of rainfall would result in an increased frequency of bankful flow conditions. Ongoing millennial climatic cyclicity (Fig. 2) forecasts that river valleys will be affected by repeated catastrophic flooding. Given that these valleys were ur- banised on the basis of a constant river water regime, serious damage to the consolidated socio-economic organisation of central-northern Europe would therefore result.

\section{REFERENCES}

Allocca, F., Amato, V., Coppola, D., Giaccio, B., Ortolani F. and Pagliuca, S., 2000: Cyclical ClimaticEnvironmental Variations during the Holocene in Campania and Apulia: Geoarcheological and Paleoethnological Evidence. Mem. Soc. Geol. It., 55, 345-352.

Brazdil, R., Glaser, R., Pfister, C. and Stangl, H., 2002 Floods in Europe. A look into the past. Pages News, 10/3, 21-23

Jirikovic, J. L., and Damon, P. E., 1994: The Medieval solar activity maximum. Climatic Change, 26, 309-316.

Ortolani, F. and Pagliuca, S., 2001: Le variazioni climatiche storiche e la prevedibilità delle modificazioni relative all'effetto serra. Asociazione Italiana Nucleare, marzo 2001, Roma.

Stuiver, M., Braziunas, T. F., Becker, B. and Kromer, B., 1991: Climatic, Solar, Oceanic and Geomagnetic influences on late glacial and Holocene Atmospheric 14C/12C change. Uuaternary Research, 35, 1-24.

\title{
Abrupt Warming of the Intermediate-Depth Atlantic Ocean in Response to Thermohaline Circulation Slowdown During the Last Deglaciation
}

\author{
Carsten Rühlemann, Stefan Mulitza, Gerrit Lohmann, André Paul, Matthias Prange, Gerold Wefer \\ Department of Geosciences and Research Center Ocean Margins, University of Bremen, 28334 Bremen, Germany; ruehl@uni-bremen.de; \\ smul@palmod.uni-bremen.de
}

Climate modeling studies predict that anthropogenic increases in greenhouse-gas concentrations will possibly cause a weakening or even a shut-down of the meridional overturning circulation in the Atlantic (thermohaline circulation, THC), through global warming and an intensification of the hydrological cycle (Cubasch et al., 2001). Therefore it is essential to monitor the Atlantic THC, preferably on a permanent basis. Present field observations of the THC, however, are insufficient to detect whether its strength is changing. Climate models exhibit pronounced and rapid warming of the tropical intermediate-depth Atlantic Ocean in consequence of a THC slowdown, suggesting that mid-depth Atlantic temperatures may serve as an indicator of THC change. Applying different forcings to an ocean general circulation model, representing present-day and glacial climates, we show that this mid-depth water response is a robust feature in both climatic situations (Fig. 1). Given that dramatic changes of the THC occurred during the last deglaciation, the reconstruction of Atlantic intermediate-depth temperatures from sediment cores provides an opportunity to evaluate the reliability of the model simulations and the suitability of tropical mid-depth Atlantic temperature change as a tracer of THC strength. For this purpose we studied two sediment cores recovered from high accumulation areas, southeast of the island of Grenada (M35003-4; 1205' N, 61ำ' W; 1299 $\mathrm{m}$ water depth) and off the coast of
Angola (ODP 1078C; $11^{\circ} 55^{\prime} \mathrm{S}, 13^{\circ} 24^{\prime}$ E; $426 \mathrm{~m}$ water depth). Site M35003 is located in the transition zone between Antarctic Intermediate Water and Upper North Atlantic Deep Water while ODP Site $1078 \mathrm{C}$ is situated within the South Atlantic Central Water. In order to reconstruct intermediate-depth temperatures for the last deglaciation we measured the oxygen isotope composition of the endobenthic foraminifer Bolivina dilatata along ODP core $1078 \mathrm{C}$ with an average temporal resolution of 65 years for the time interval 24,000 to 8,000 calendar years before present (24 - 8 cal. kyr BP). The $\delta^{18} \mathrm{O}$ record of the benthic foraminifera Cibicidoides wuellerstorfi for the Caribbean core M35003-4 (Hüls, 2000 ) has an average resolution of 330 years. 


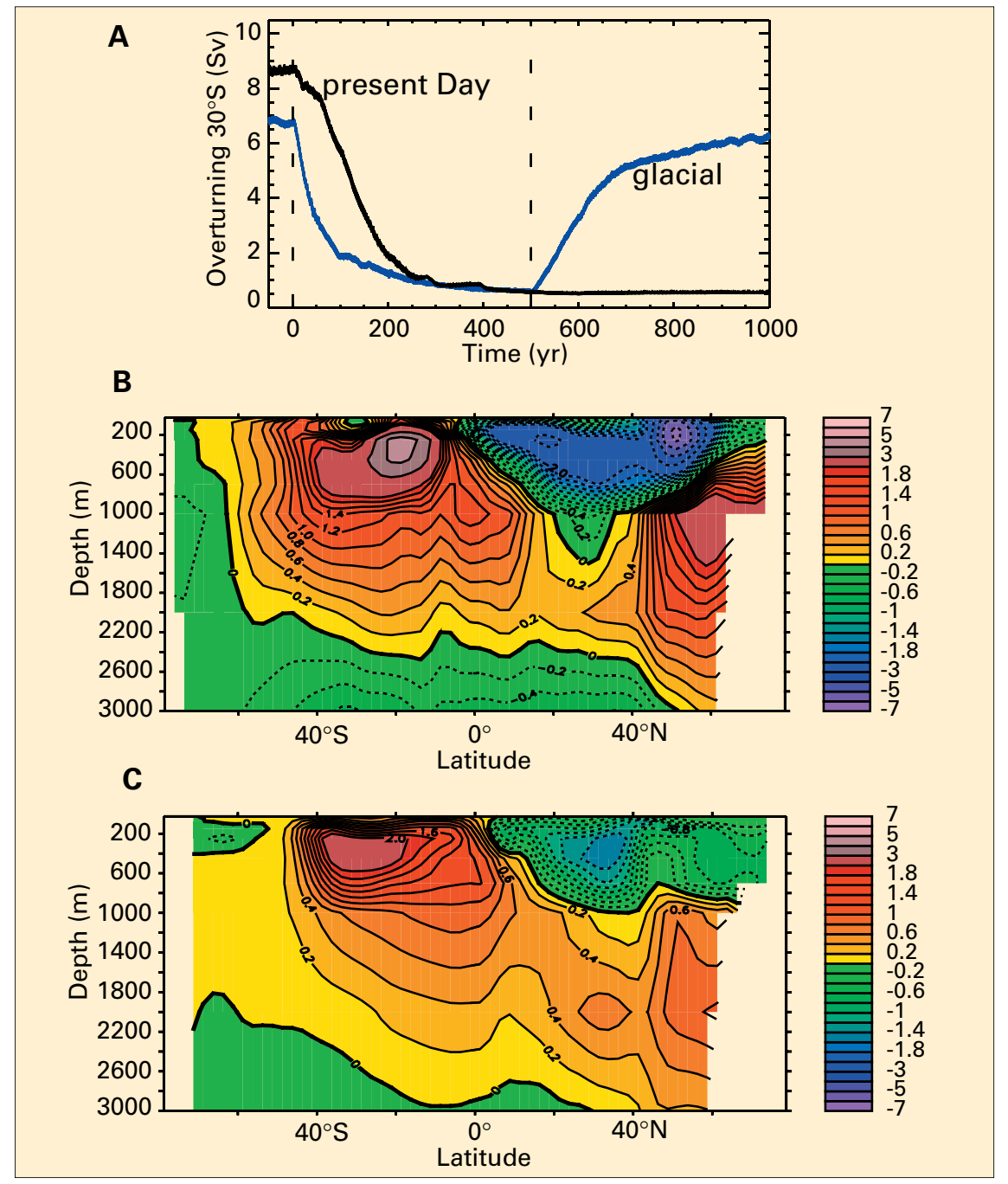

Fig. 1: Change of overturning strength and temperature in meltwater perturbation experiments using a hybrid-coupled model for present-day and glacial climate conditions. The model is designed as follows: The atmosphere model ECHAM3/T42 is forced by present-day observed or reconstructed (CLIMAP with $3^{\circ} \mathrm{C}$ additional cooling in the tropics) sea surface temperatures. Computed fields of surface air temperature, freshwater flux and wind stress are then used to drive an improved version of the ocean general circulation model LSG. The applied heat flux formulation allows for scale-selective damping of temperature anomalies. (a) Temporal evolutions of the Atlantic meridional overturning circulation. A meltwater input of $0.15 \mathrm{~Sv}$ is applied to the North Atlantic between $40^{\circ} \mathrm{N}$ and $55^{\circ} \mathrm{N}$ from year 0 to year 500 . After termination of the anomalous freshwater forcing, the present-day circulation remains in the "off" mode, whereas the glacial circulation recovers. This mono-stable behavior of the glacial THC has been discussed by Prange et al. (2002). (b) Zonally averaged temperature change (in ${ }^{\circ} \mathrm{C}$ ) at year 500 (end of the meltwater perturbation) relative to the unperturbed state for the present-day Atlantic Ocean. Between $-2^{\circ} \mathrm{C}$ and $+2^{\circ} \mathrm{C}$ the contour interval is $0.2^{\circ} \mathrm{C}$, for larger anomalies the interval is $1^{\circ} \mathrm{C}$. (c) Same as in (b) but for the glacial Atlantic.

We corrected the benthic isotope records by subtracting the global $\delta^{18} \mathrm{O}$ ice effect caused by the melting of continental ice and freshwater runoff during the last deglaciation. The residual $\delta^{18} \mathrm{O}$ curve $\left(\delta^{18} \mathrm{O}\right)$ shows rapid and pronounced decreases of 0.5 to $0.9 \%$ at the beginning of Heinrich event $\mathrm{H} 1$ (17 cal. kyr BP) and at the Younger Dryas (13 cal. kyr BP) (Figs. 2c and 2d); climatic periods when deep water formation was greatly reduced (Clark et al., 2002) (Fig. 2b). These $\delta^{18} \mathrm{O}$ shifts could either reflect increase position of ODP core $1078 \mathrm{C}$ is even smaller (<0.1 psu). Consequently, the major proportion of the benthic $\delta^{18} \mathrm{O}$ shifts at Heinrich event $\mathrm{H} 1$ and the Younger Dryas must be explained by warming of $1-3^{\circ} \mathrm{C}$ when a decrease in $\delta^{18} \mathrm{O}$ of $0.22 \%$ 。 per $1{ }^{\circ} \mathrm{C}$ temperature increase is applied. The rate of intermediate depth warming at the onset of Heinrich event $\mathrm{H} 1$ and the Younger Dryas (averaged between 12.9 and 12.2 cal. kyr BP) is 0.8 and $0.7^{\circ} \mathrm{C}$ century $^{-1}$, respectively.

The relationship between the strength of the THC and tropical Atlantic intermediate-depth temperatures during the last deglaciation may be highly relevant for tracing present-day and future changes of the THC. Freshening of the North Atlantic (Dickson et al., 2002) and a concomitant reduction in the Iceland-Scotland overflow (Hansen et al., 2001) over the past four to five decades suggests that a weakening of the THC might already be under way. Akin to the oceanographic processes during the last deglaciation we expect that a slowing of the THC is accompanied by a warming of tropical Atlantic intermediate-depth waters. Indeed, section data from the 1920s through the 1990s in the Atlantic Ocean reveal a considerable warming trend of $0.5^{\circ} \mathrm{C}$ century ${ }^{-1}$ between 1000 and $2000 \mathrm{~m}$ water depth for latitudes between $32^{\circ} \mathrm{S}$ and $36^{\circ} \mathrm{N}$ (Arbic and Owens, 2001). Arbic and Owens (2001) show that this warming in the tropical North Atlantic over the past decades is associated with a downward displacement of isopycnals which they ascribe to a volumetric increase of Labrador Sea Water (LSW) at the expense of deep water from the overflow across the Greenland-Scotland Ridge. In fact, such a change in volumes can explain a downward shift of isopycnals only below the depth of LSW. The isopycnal displacement at 1000 $\mathrm{m}$, however, must be caused by other mechanisms. We argue that a slowdown of the thermohaline overturning is the most likely explanation for the tropical intermediate-depth warming in the Atlantic Ocean. Disturbing our model of the 


\section{Science Highlights}

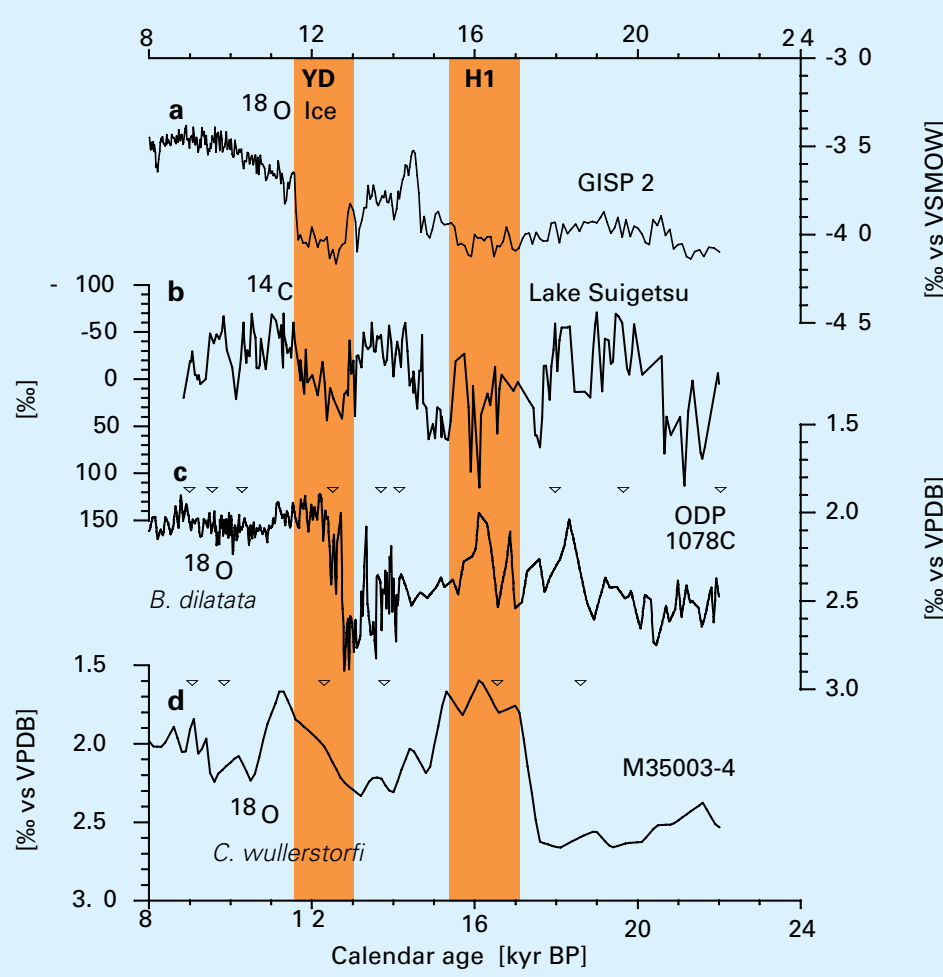

Fig. 2: Comparison of oxygen isotope ratios of the benthic foraminifera B. dilatata (c) and C. wuellerstorfi (d) (Hüls, 2000) from sediment cores ODP $1078 \mathrm{C}\left(11^{\circ} 55^{\prime} \mathrm{S}, 1^{\circ} 24^{\prime} \mathrm{E} ; 426 \mathrm{~m}\right.$ water depth) and M35003-4 (12 ${ }^{\circ} 5^{\prime}$ N, 61 $1^{\circ} 15^{\prime} \mathrm{W}$; $1299 \mathrm{~m}$ water depth), respectively, indicating tropical Atlantic intermediate-depth temperatures, with (a) oxygen isotopes from the GISP2 ice core displaying air temperatures over Greenland, and (b) atmospheric radiocarbon from sediments of Lake Suigetsu, Japan (Kitagawa et al. 2000; adapted from Clark et al., 2002). ${ }^{14} \mathrm{C}$ AMS control points for ODP 1078C and M35003-4 are denoted by triangles above the respective record. $\mathrm{H} 1$ and YD denote Heinrich event H1and the Younger Dryas period, respectively. The record of $\Delta^{14} C_{a t m}$ (b) is a function of the production rate of ${ }^{14} \mathrm{C}$ in the upper atmosphere and the sizes of and exchange rates between the major carbon reservoirs. North Atlantic Deep Water (NADW) is presently the major source of ${ }^{14} \mathrm{C}$ to the deep sea, and changes in the strength of this water mass probably dominate the variations in $\Delta^{14} C_{a t m}$. Positive anomalies in the $\Delta^{14} C_{\text {atm }}$ record hence largely reflect reduction of NADW production and thermohaline overturning (Clark et al., 2002).

present-day circulation with a weak North Atlantic freshwater flux of $0.03 \mathrm{~Sv}\left(1 \mathrm{~Sv}=10^{6} \mathrm{~m}^{3} \mathrm{~s}^{-1}\right)$, we find that the observed mid-depth warming rate in the low-latitude Atlantic (Arbic and Owens, 2001) is consistent with a weakening of the THC by only $5-15 \%$ (not shown here).

In view of uncertain Atlantic overturning reduction, it is inevitable to design a proper strategy for the early detection of THC change. Intermediate-depth waters provide a potentially sensitive indicator of anthropogenic climate change related to the THC, which has shown to be one of the most uncertain processes of possible future climate shifts. A primary objective of several climate research programs is to design practical strategies for monitoring climate variability and
THC changes. Using a novel combination of paleoceanographic records, climate modeling results and recent oceanographic evidence we highlight the importance to include long-term temperature measurements of the low latitude mid-depth Atlantic as an integrative indicator ofTHC change in such a monitoring system. We argue that the rates of temperature change of intermediate-depth waters at Heinrich event $\mathrm{H} 1$ and the Younger Dryas provide a benchmark against which to assess warming rates in the $20^{\text {th }}$ century as well as in the future.

\section{ACKNOWLedgments}

This research was funded by the Bundesministerium für Bildung und Forschung. More information about the projects DEKLIM and RASTA can be found under www.deklim.de and www.geomar.de/ projekte/rasta/.

\section{REFERENCES}

Arbic, B.K., and Owens, W.B., 2001: Climatic warming of Atlantic intermediate waters, Journal of Climate, 14, 4091-4108.

Clark, P.U., Pisias, N.G., Stocker, T.F. and Weaver, A.J., 2002: The role of the thermohaline circulation in abrupt climate change, Nature, 415, 863-869.

Dickson, B., Yashayaev, I., Meincke, J., Turrell, B. Dye, S., and Holfort, J., 2002: Rapid freshening of the deep North Atlantic Ocean over the past four decades, Nature, 416, 832-837.

Hansen, B., Turrell, W.R. and Osterhus, S., 2001: Decreasing overflow from the Nordic seas into the Atlantic Ocean through the Faroe Bank channel since 1950, Nature, 411, 927-930.

Hüls, M., 2000: Millennial-scale SST variability as inferred from planktonic foraminifera sensus counts in the western subtropical Atlantic, GEOMAR Report, GEOMAR Research Center for Marine Geosciences, Christian Albrechts University in Kiel, 95: 118 pp.

For full references please consult:

www.pages-igbp.org/products/newsletters/ref2003_1.html

\section{Past Rates of Sea Level Change}

\section{NICK HARVEY}

University of Adelaide, South Australia, 5005, Australia; nick.harvey@adelaide .edu.au

Rates of sea level change identified from the geological record can be separated into longer-term $(<1,000 \mathrm{ka})$, the post-glacial marine transgression (20 ka to $7 \mathrm{ka}$ ) and the subsequent adjustment to modern levels ( $>7 \mathrm{ka}$ ). In addition, there are historic rates from instrument measurements.

\section{$<1,000 \mathrm{ka}$}

Long term geological rates of sealevel change provide a perspective on the cyclical nature of sea level and the extent to which current and predicted sea-level changes are perturbations from natural cycles. Oxygen isotope $\left({ }^{18} \mathrm{O} /{ }^{16} \mathrm{O}\right)$ ratios of planktonic foraminifera from deep-sea sediments provide evidence of sea level fluctuations over numerous glacial/interglacial cycles with the Vostok ice core providing additional detailed records for the last four cycles. An approximate 100 ka periodicity for these cycles has been identified in the geological record and correlated 